\title{
Fluorescence-guided development of a tricistronic vector encoding bimodal optical and nuclear genetic reporters for in vivo cellular imaging
}

Adam Badar ${ }^{1 *+}$, Louise Kiru ${ }^{1,2+}$, Tammy L Kalber ${ }^{1}$, Amit Jathoul ${ }^{2}$, Karin Straathof ${ }^{2}$, Erik Årstad ${ }^{3}$, Mark F Lythgoe ${ }^{1 \dagger}$ and Martin Pule ${ }^{2 \dagger}$

\begin{abstract}
Background: In vivo imaging using genetic reporters is a central supporting tool in the development of cell and gene therapies affording us the ability to selectively track the therapeutic indefinitely. Previous studies have demonstrated the utility of the human norepinephrine transporter (hNET) as a positron emission tomography/single photon emission computed tomography (PET/SPECT) genetic reporter for in vivo cellular imaging. Here, our aim was to extend on this work and construct a tricistronic vector with dual optical (firefly luciferase) and nuclear (hNET) in vivo imaging and ex vivo histochemical capabilities. Guiding this development, we describe how a fluorescent substrate for hNET, 4-(4-(dimethylamino)styryl)-N-methylpyridinium $\left(\mathrm{ASP}^{+}\right)$, can be used to optimise vector design and serve as an in vitro functional screen.
\end{abstract}

Methods: Vectors were designed to co-express a bright red-shifted firefly luciferase (FLuc), hNET and a small marker gene RQR8. Genes were co-expressed using 2A peptide linkage, and vectors were transduced into a T cell line, SupT1. Two vectors were constructed with different gene orientations; FLuc.2A.RQR8.2A.hNET and hNET.2A.FLuc.2A. RQR8. hNET function was assessed using $\mathrm{ASP}^{+}$-guided flow cytometry. In vivo cellular conspicuity was confirmed using sequential bioluminescence imaging (BLI) and SPECT imaging of transduced SupT1 cells injected into the flanks of mice.

Results: SupT1/FLuc.2A.RQR8.2A.hNET cells resulted in >4-fold higher ASP ${ }^{+}$uptake compared to SupT1/hNET.2A. FLuc.2A.RQR8, suggesting that 2A orientation effected hNET function. SupT1/FLuc.2A.RQR8.2A.hNET cells were readily visualised with both BLI and SPECT, demonstrating high signal to noise at $24 \mathrm{~h}$ post ${ }^{123}{ }^{-}$-meta-iodobenzylguanidine (MIBG) administration.

Conclusions: In this study, a pre-clinical tricistronic vector with flow cytometry, BLI, SPECT and histochemical capabilities was constructed, which can be widely applied in cell tracking studies supporting the development of cell therapies. The study further demonstrates that hNET function in engineered cells can be assessed using $\mathrm{ASP}^{+}$-guided flow cytometry in place of costly radiosubstrate methodologies. This fluorogenic approach is unique to the hNET PET/SPECT reporter and may prove valuable when screening large numbers of cell lines or vector/mutant constructs.

Keywords: Reporter genes; SPECT; PET; BLI; Cell imaging; Multimodality imaging; Norepinephrine transporter; ASP+

\footnotetext{
* Correspondence: a.badar@ucl.ac.uk

${ }^{\dagger}$ Equal contributors

'Division of Medicine, Centre for Advanced Biomedical Imaging (CABI), University College London, 72 Huntley Street, London WC1E 6DD, UK Full list of author information is available at the end of the article
} 


\section{Background}

Cellular therapy with engineered cells is a promising area and is finding increasing application in regenerative medicine and cancer adoptive immunotherapy. In the clinical setting, T cell-based studies using chimeric antigen receptor (CAR) therapy have shown outstanding efficacy in refractory cancers [1-4]. More broadly, induced progenitor cells have been shown to regenerate different organs and systems in neurodegenerative [5], cardiovascular [6,7] and musculoskeletal [8] disorders. These therapeutics are different from standard therapies such as small molecules or proteins: they are essentially living therapies with no half-life, a complex engraftment and multifaceted in vivo behaviour.

A key limitation of pre-clinical and clinical development of advanced cellular therapies is lack of a satisfactory method for tracking these cells over sufficiently long periods of time. Direct or transient labelling methods, such as iron-labelled cells for magnetic resonance imaging (MRI) or ${ }^{111}$ In-oxine-labelled cells for single photon emission computed tomography (SPECT) are unsuitable for the time frame of immunotherapy studies. These allow imaging over hours/days [9-14], which are insufficient to study the complex biological integration and efficacy of cellular therapies, which can evolve over many weeks and months. A credible option is selective genetic modification of cells with a marker gene, using an integrating vector, to selectively track the cellular therapeutic indefinitely. Several different approaches to genetic reporter imaging have been proposed $[15,16]$. As a translational approach, positron emission tomography (PET) or SPECT show most promise. One such PET/SPECT genetic reporter is the human norepinephrine transporter (hNET) [17]. In combination with radiolabelled noradrenaline analogues, meta-iodobenzylguanidine (MIBG) or metahydroxyephedrine (mHED), hNET engineered cells can be mapped in vivo via SPECT $\left({ }^{123} \mathrm{I}-\mathrm{MIBG}\right)$ or PET $\left({ }^{124} \mathrm{I}\right.$ MIBG, ${ }^{11} \mathrm{C}$-mHED) [17-19]. It has been demonstrated that the technique has quantitative capabilities and has been used in longitudinal imaging studies of adoptively transferred T cells and gene therapy [20,21].

Here our aim was to construct a tricistronic vector coexpressing hNET with firefly luciferase (FLuc) and a compact suicide/marker gene, RQR8 [22]. This triple construct extends upon the previously designed hNETeGFP bicistronic construct [18]. The hNET-FLuc construct is a novel addition for in vivo bioluminescence imaging (BLI), and the triple construct of hNET-FLucRQR8 has potential for histochemistry and therapeutic application. In this study, several vector constructs were designed and tested. Screening for a lead construct, we show that hNET function can be assessed in vitro using $\mathrm{ASP}^{+}$, a fluorescent analogue of the neurotoxin $\mathrm{MPP}^{+}$ and hNET substrate $[23,24]$, in place of conventional and costly radiosubstrate methodologies. Using this approach, we determined the optimal gene orientation of the tricistronic construct. Finally, we performed sequential BLI and ${ }^{123}$ I-MIBG SPECT in vivo imaging.

\section{Methods \\ Generation of tricistronic retroviral vectors and transduction of SupT1 cells}

All cell culture medium and supplements were obtained from Lonza BioWhittaker (Walkersville, USA) unless otherwise stated. A human T cell lymphoblastic lymphoma-derived cell line (SupT1) was obtained from the American Type Culture Collection (ATCC, University Boulevard Manassas, USA) and cultured in RPMI 1640 media (St. Louis, USA) supplemented with $10 \%$ foetal bovine serum (FBS) and GlutaMAX (Gibco, Grand Island, USA). Cell lines were maintained at $37^{\circ} \mathrm{C}$ in a humidified $5 \% \mathrm{CO}_{2}$ atmosphere. Three SupT1 cell populations were engineered, each with a different expression cassette; (1) an IRES-based bisictronic vector encoding for hNET and a cell surface marker CD34 (vector 1: SupT1/hNET.I.CD34), (2) a 2A peptide-linked tricistronic vector encoding for hNET, red-shifted codon optimised FLuc [25] and a highly compact marker/suicide gene RQR8 [22] with 2A linkage at the N-terminus of hNET (vector 2: SupT1/FLuc.2A.RQR8.2A.hNET) and (3) at the C-terminus hNET (vector 3: SupT1/hNET.2A. FLuc.2A.RQR8). Moloney murine leukaemia virus (MoMuLV) long terminal repeat (LTR) promoter was used. SupT1 cells were transduced with RD114 pseudotyped supernatant generated from transfection of HEK-293T cells with the expression plasmids supplying Gagpol (gift from Elio Vanin, Baylor College of Medicine), RD114 envelope (gift from Mary Collins, University College London) PeqPam-env and each of the three hNET encoding vectors above. Transduction efficiency was determined by flow cytometry with $\alpha$ CD34-APC staining for vector 1 and QBEnd10 staining as previously described [22] for vectors 2 and 3.

\section{Optimisation of staining conditions for $\mathrm{ASP}^{+}$-guided flow cytometry}

SupT1 cells $\left(1 \times 10^{6}\right)$ transduced with hNET vector 1 were incubated at $37^{\circ} \mathrm{C}$ with varying concentrations of $\mathrm{ASP}^{+}\left(1 \times 10^{-3}, 5 \times 10^{-3}, 1 \times 10^{-2}, 5 \times 10^{-2}, 0.1,0.5,1\right.$ $\mu \mathrm{M})$ for $10,30,60,120$ and $240 \mathrm{~min}$. The cells were washed once with fluorescence activate cell sorting (FACS) buffer containing 1\% FBS, phosphate saline buffer (PBS) and $50 \mathrm{mg} / \mathrm{mL}$ Normocin (InvivoGen, San Diego, USA). The supernatant was discarded and cells were re-suspended in $500 \mu \mathrm{L}$ of FACS buffer. Flow cytometry was performed using Beckman Coulter Cyan instrument (Beckman Coulter, Brea, USA). 


\section{$\mathrm{ASP}^{+}$-guided flow sorting and functional assessment of hNET expressing SupT1 cells}

Optimal $\mathrm{ASP}^{+}$staining conditions determined above were used for $\mathrm{ASP}^{+}$-guided flow sorting of SupT1 cell lines expressing the three hNET vector constructs. Cells were prepared as described above. $\mathrm{ASP}^{+}$mean fluorescence intensities (MFI) were determined preand post-FACS (Beckman Coulter MoFlo-XDP) using areas under the curve and subtracting any non-specific signal from non-transduced SupT1 (SupT1/NT) cell populations. Measurements were acquired in triplicates for each cell line and statistical significance of differences between mean values was obtained with IBM SPSS software using the one-way ANOVA and the Tukey's HSD test.

\section{In vitro radiotracer uptake assay}

SupT1 cells expressing vectors 1 and 2 were further characterised by radiosubstrate uptake studies. $1 \times 10^{6}$ SupT1/hNET.I.CD34, SupT1/FLuc.2A.RQR8.2A.hNET and SupT1/NT cells were incubated for $30 \mathrm{~min}$ at $37^{\circ} \mathrm{C}$ with $\left[{ }^{125} \mathrm{I}\right]-$ MIBG $(7.4 \mathrm{kBq})$. The cells were rapidly washed twice with $500 \mu \mathrm{L}$ ice-cold PBS and the supernatant collected. Cell pellets were resuspended in $1 \mathrm{~mL}$ PBS. Radioactive uptake was determined by gamma counting (WIZARD, PerkinElmer, Beaconsfield, UK) of the resuspended cells and corresponding supernatants. Percentage $\left[{ }^{125} \mathrm{I}\right]-\mathrm{MIBG}$ cell uptake was calculated by dividing the counts in the cell pellet by the total counts (counts in cell pellet + counts in supernatant). All experiments were performed in triplicates. The one-way ANOVA and the Tukey's HSD test were used to determine the significance of differences between mean values.

\section{In vivo bioluminescence and SPECT/CT imaging}

All animal procedures were carried out in accordance with the UK Animals (Scientific Procedures) 1986 Act and institutional ethics regulation. SupT1/FLuc.2A. RQR8.2A.hNET cells $\left(5 \times 10^{6}\right)$ or non-transduced SupT1 cells $\left(5 \times 10^{6}\right)$ were injected into the subcutaneous space of the right flank of NOD/SCID mice $(n=3$ in each group). Seven days later, BLI images (Biospace photon imager Optima system, Paris, France) were acquired 15 min post-intraperitoneal administration of $200 \mu \mathrm{L}$ of DLuciferin $(10 \mathrm{mg} / \mathrm{mL})$ using a $50 \mathrm{~mm}$ CCD lens with a sensitivity of 37 photons $/ \mathrm{s} / \mathrm{sr} / \mathrm{cm}^{2}$. Images were analysed using Biospace M3 Vision software. $15 \mathrm{MBq}(150 \mu \mathrm{L})$ of $\left[{ }^{123} \mathrm{I}\right]$-MIBG (Mallinckrodt, Northampton, UK) was subsequently administered to animals via tail vein followed by whole body SPECT/CT imaging (nanoSPECT silver upgrade, Mediso, Budapest, Hungary) at $1 \mathrm{~h}, 4 \mathrm{~h}$ and 24 $h$ post injection. Images were reconstructed using $\mathrm{HiS}$ PECT software (InviCRO, Boston, USA) followed by image processing and analysis using VivoQuant Software (InviCRO, Boston, USA).

\section{Results}

$\mathrm{ASP}^{+}$-guided flow cytometry enables functional assessment of hNET engineered cells

Functional determination of hNET vectors requires costly and complex radiochemistry work. We hypothesised that the fluorescent NET substrate $\mathrm{ASP}^{+}$could allow determination of hNET function based on flow cytometry. A concentration and time-course titration assay was designed to determine optimised conditions for efficient cell staining and sorting of hNET expressing cells using $\mathrm{ASP}^{+}$. hNET expressing and non-transduced SupT1 cells were compared to quantify non-specific uptake (Figure 1). Adequate discrimination between specific and non-specific $\mathrm{ASP}^{+}$staining is essential to study efficiency of hNET encoding vector transduction and reporter function and to facilitate isolation of pure hNET positive cell populations. We determined that $\mathrm{ASP}^{+}$is both specifically and non-specifically taken up by cells (Figure 1). We observed good discrimination of specific and non-specific staining with a two-log shift in fluorescence. Optimal separation between hNET positive and hNET negative cells, using minimum incubation time and $\mathrm{ASP}^{+}$concentration, was $30 \mathrm{~min}$ and $0.05 \mu \mathrm{M} \mathrm{\textrm {ASP } ^ { + }}$ (Figure 1).

\section{Tricistronic pre-clinical vector for histochemistry, BLI and SPECT tracking of engineered cells}

We constructed a tricistronic vector which allows engineered cells to be tracked in vivo by BLI and SPECT/ PET and ex vivo by histochemistry. We co-expressed a bright red-shifted firefly luciferase, along with the hNET and RQR8 - a small marker gene which binds the widely used antibody QBEnd/10 enabling flow cytometry and histochemistry. We used 2A peptide linkage to drive obligate stoichiometric co-expression [26]. Two candidate tricistronic vector constructs were designed and tested; one with $2 \mathrm{~A}$ peptide linkage at the $\mathrm{N}$-terminus of hNET (FLuc.2A.RQR8.2A.hNET) and one at the C-terminus (hNET.2A.FLuc.2A.RQR8). RQR8 function and transduction efficiency of the two vectors was verified via flow cytometry and QBEnd10 staining. As a reference, SupT1 cells encoding an IRES linked bicistronic vector (SupT1/hNET.I.CD34) were used. Using the optimal staining conditions determined above, $\mathrm{ASP}^{+}$-guided FACS was performed to isolate hNET positive SupT1 cells by gating on the brightest $5 \%$ of each population. Post sorting, positive $\mathrm{ASP}^{+}$staining increased from $59.4 \%$ to $99 \% \pm 0.01 \%$ for SupT1/hNET.l.dCD34, $46.2 \%$ to $93.6 \% \pm 0.34 \%$ for SupT1/FLuc.2A.RQR8.2A.hNET, and $52.4 \%$ to $93.6 \% \pm 0.66 \%$ for SupT1/hNET.2A. FLuc.2A.RQR8 (Figure 2). No difference in growth rates 


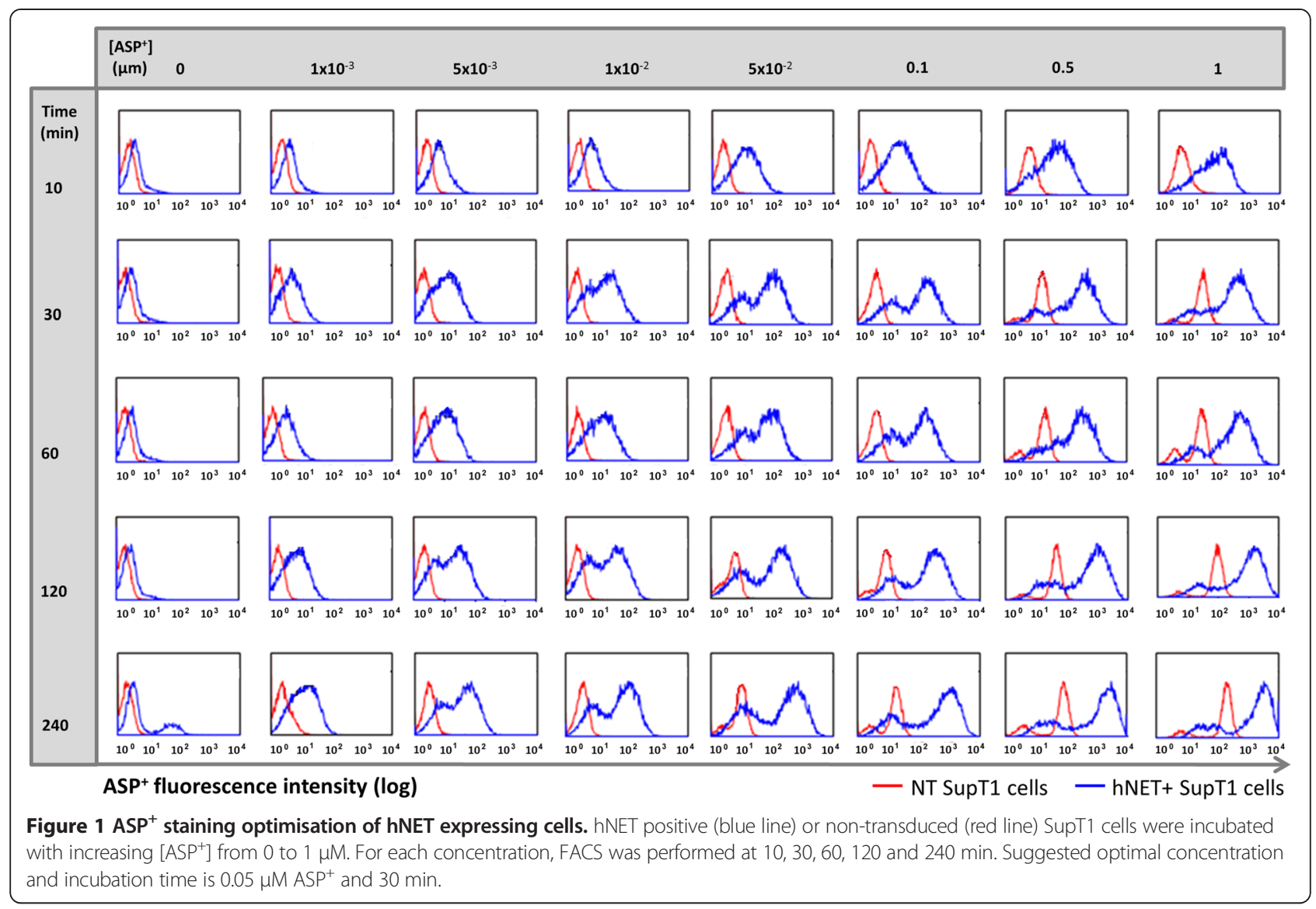

were observed in all cell lines compared to nontransduced SupT1 control cells. hNET function in all cell lines was tested over a period of 17 weeks via $\mathrm{ASP}^{+}$-guided FACS without any significant reduction in uptake observed (Additional file 1: Table S1).

\section{$\mathrm{ASP}^{+}$screening to assess $2 \mathrm{~A}$ peptide linkage orientation and hNET function}

Interestingly, using $\mathrm{ASP}^{+}$, we found that $2 \mathrm{~A}$ orientation within the tricistronic vector affected hNET function. Sorted SupT1/FLuc.2A.RQR8.2A.hNET and SupT1/ hNET.2A.FLuc.2A.RQR8 cells were subject to $\mathrm{ASP}^{+}$-guided flow cytometry with mean fluorescence intensities measured as from the AUC. Despite resulting in a 1.7-fold lower MFI compared to the bicistronic reference cells (SupT1/hNET.l.dCD34), cells encoding the tricistronic vector with $2 \mathrm{~A}$ at the N-terminus of hNET (SupT1/ FLuc.2A.RQR8.2A.hNET) gave rise to a $>4$-fold higher MFI (2292.33 $\pm 80.39 \mathrm{MFI})$ compared to cells encoding 2A at the C-terminus of hNET (SupT1/hNET.2A.FLuc.2A. RQR8) $(549 \pm 20.43$ MFI) (Figure 3a). hNET function in SupT1/FLuc.2A.RQR8.2A.hNET cells was further characterised via radiosubstrate uptake assay. These cells demonstrated $>18$-fold higher ${ }^{125}$ I-MIBG uptake $(60.25 \% \pm$ $1.34 \%)$ compared to non-hNET expressing control cells (SupT1/NT) $(3.18 \% \pm 0.37 \%)$. Similar to $\mathrm{ASP}^{+}$accumulation profiles, ${ }^{125}$ I-MIBG uptake in SupT1/FLuc.2A. RQR8.2A.hNET was 1.2-fold lower than in SupT1/hNET.l. dCD34 cells, suggesting reduced hNET pumping capabilities due to higher genetic load on tricistronic compared to bicistronic vector.

\section{In vivo imaging of the tricistronic vector}

As an initial in vivo validation of the hNET encoding tricistronic bimodal imaging vector, $5 \times 10^{6}$ SupT1/ hNET.2A.FLuc.2A.RQR8 cells were inoculated into the flanks of immunocompromised mice and imaged 7 days later via BLI followed by SPECT/CT. Following luciferin administration, bioluminescence was clearly visible in the right flank (Figure 4a) $\left(3.25 \times 10^{7} \pm 9.11 \times 10^{2}\right.$ CPM) indicating cell viability and FLuc function. Following intravenous tail vein injection of ${ }^{123} \mathrm{I}-\mathrm{MIBG}$, dynamic whole body SPECT/CT images were collected at $30 \mathrm{~min}, 4 \mathrm{~h}$ and $24 \mathrm{~h}$ (Figure $4 \mathrm{~b}, \mathrm{c}, \mathrm{d}, \mathrm{e}$ ). Consistent with 


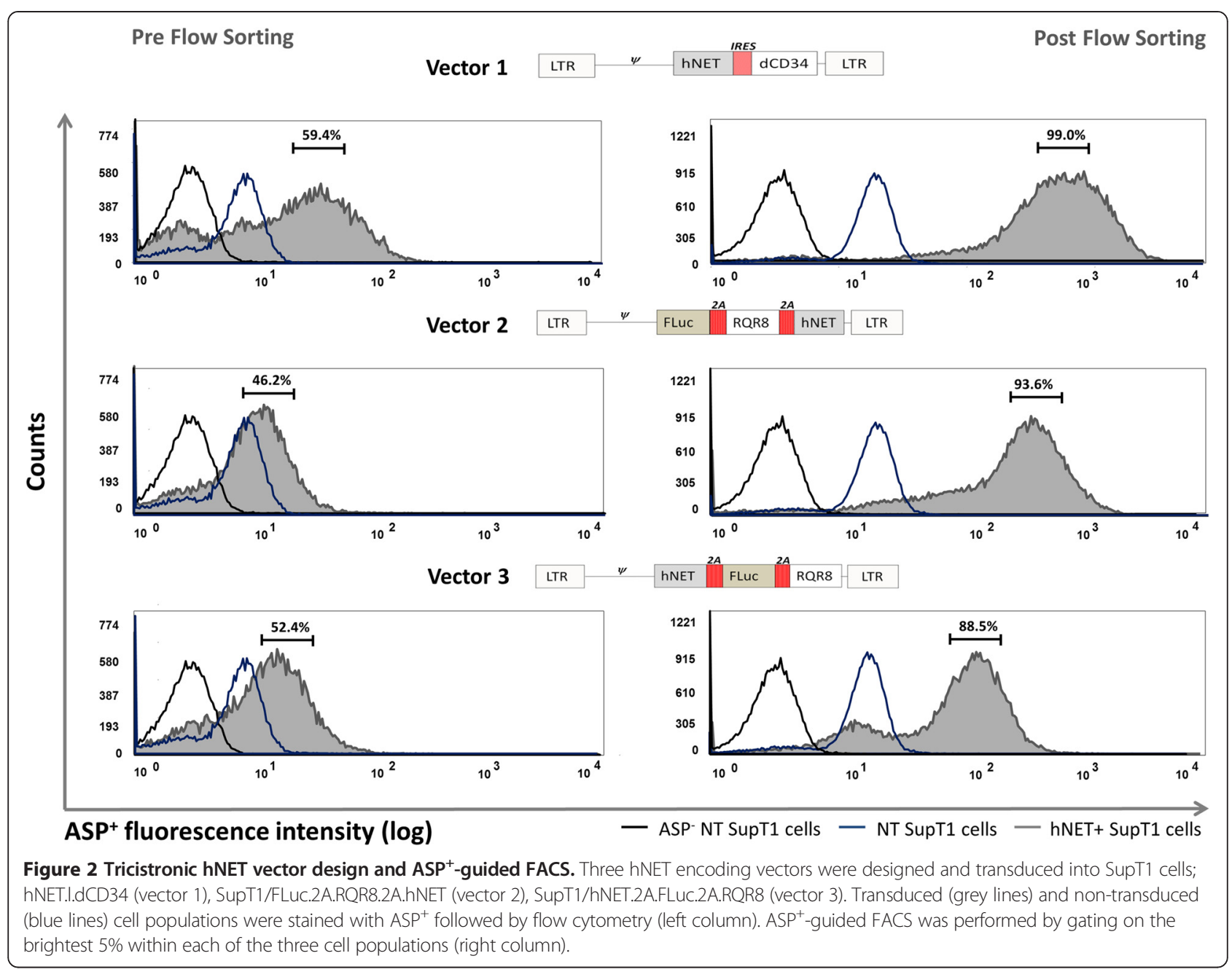

earlier reports suggesting a late imaging paradigm is favourable when imaging hNET cells with MIBG [21], good signal-to-noise was observed at $24 \mathrm{~h}$ post radiotracer administration (Figure $4 \mathrm{~d}, \mathrm{e}$ ). At the earlier time points of $30 \mathrm{~min}$ and $4 \mathrm{~h}$, renal clearance is observed with high signal in the kidneys and bladder, with increasing signal in the adrenals (high NET expressing organ) (Figure $4 \mathrm{~b}, \mathrm{c}$ ). Increasing signal was also observed in the salivary and thyroid glands (sodium iodide symporter expressing organs) due to tracer metabolism/ deiodination (Figure 4b,c,d,e). With decreased background signal at $24 \mathrm{~h}$, radiotracer accumulation in the subcutaneous tumour can clearly be seen with regional heterogeneity resolved. Percent injected dose (\% ID) of ${ }^{123}$ I-MIBG in tumours at $24 \mathrm{~h}$ post injection, as determined by drawing image-guided 3D regions of interest, was $3.12 \% \pm 0.31 \%$ ID in $\operatorname{hNET}(+)$ xenografts, and $0.019 \% \pm 0.01 \%$ ID in $\operatorname{hNET}(-)$ xenografts (equivalent to background levels).

\section{Discussion}

With the development of new cellular and gene therapies, there is a need for non-invasive, readily available methods for detecting and quantifying the fate of these therapies in animal and man. As a translational approach, PET and SPECT genetic reporters have shown promise and have supported numerous clinical trials [27-29]. Various PET/SPECT reporter proteins have been proposed including the human sodium iodide symporter (hNIS), the hNET and the herpes simplex virus thymidine kinase (HSVtk) [16,17,30,31]. Difficulties in translating these into clinic include availability of clinically approved complementary radiotracers, early planning necessary to integrate the reporter protein and imaging protocol into trial design, incorporation of the reporter gene into the vector without exceeding the packaging capacity or affecting cell function and limited sensitivity in tissues with endogenous expression of the reporter protein. 


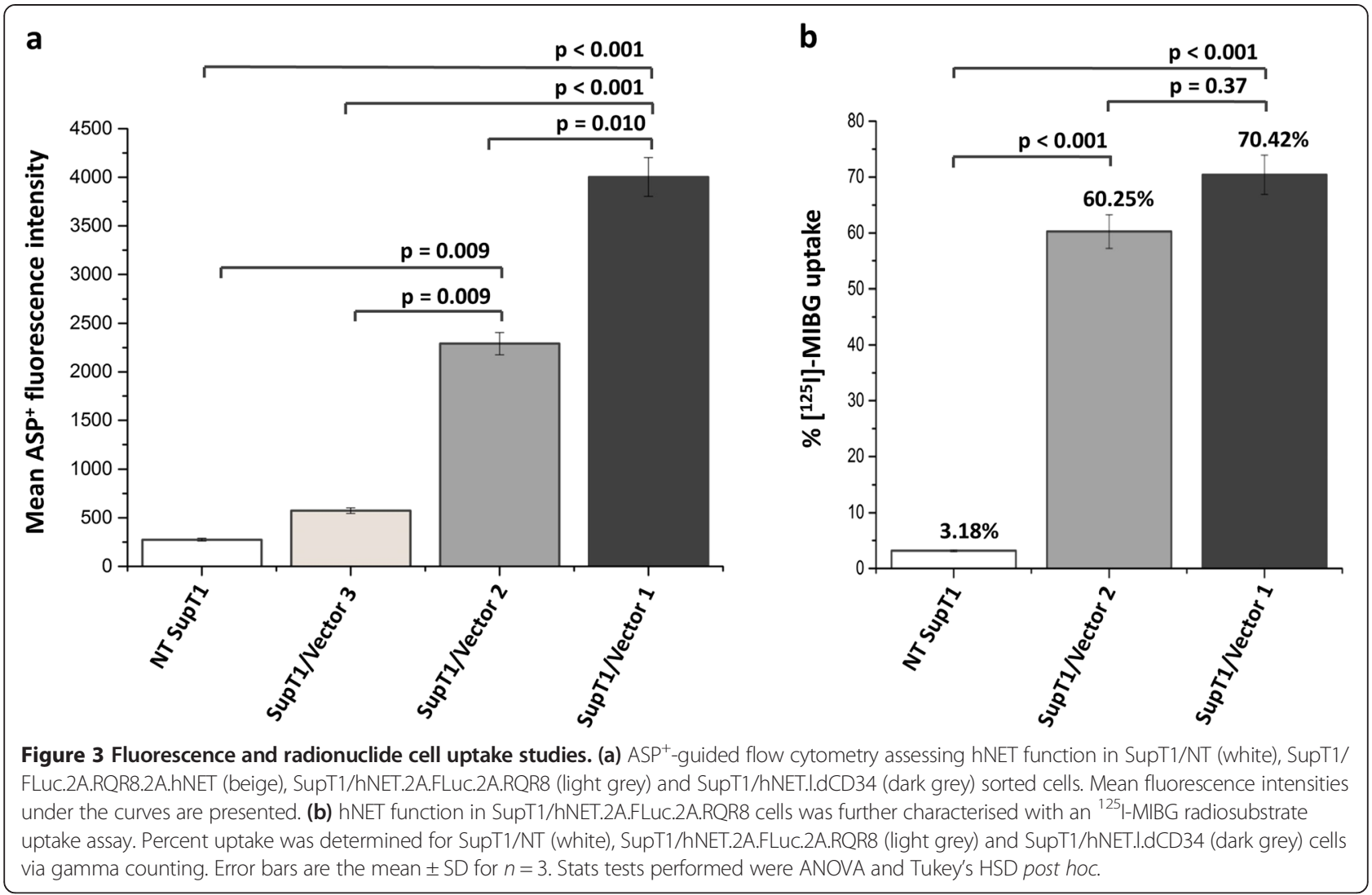

In preclinical imaging, taking advantage of the strengths each modality (e.g. MRI, optical and nuclear) has to offer, the use of multimodal multicistronic reporters is becoming increasingly popular [16]. For example, co-expression of PET and BLI reporters would enable rapid, affordable and sensitive BLI, alongside complementary tomographic and quantitative PET capabilities. Expression vectors are often composed of multiple genes (e.g. a therapeutic, a marker gene, a suicide gene and a reporter gene) some of which can be large surface proteins, which may tax the vector packaging capacity and transcriptional efficiency. Strategies which promote maximising vector space are therefore essential and may include gene and protein truncation [22,32], efficient gene coupling approaches $[33,34]$ and the utility of dual purpose genes $[22,35,36]$.

Here, we have developed a trisictronic expression vector containing a nuclear reporter (hNET), a BLI reporter (FLuc) and a highly compact dual-purpose marker/suicide gene (RQR8). To achieve a compact vector, genes were linked with the 'self-cleaving' small 2A peptide, driving obligate co-expression under a single promoter (26). Exploiting the endogenous fluorescent properties of the hNET substrate $\mathrm{ASP}^{+}$, it was possible to simultaneously, and efficiently, sort pure cell populations and evaluate reporter function. Such a system is unique to hNET as a nuclear reporter and may circumvent the need for in vitro radioligand cell uptake assays prior to in vivo use. Furthermore, as hNET positive cells can be efficiently sorted using $\mathrm{ASP}^{+}$-guided flow cytometry, hNET could double up as a marker gene, leaving more flexibility to insert other genes in the expression vector.

Using $\mathrm{ASP}^{+}$-guided flow cytometry, we demonstrated that residual $2 \mathrm{~A}$ amino acids attached to the C-terminus of the transcribed hNET markedly reduced the protein capacity to accumulate substrate into the cell. This finding further corroborates previous structure/function studies indicating the critical contribution of the hNET C-terminus to transporter trafficking, stability and function [37,38]. Consequently, an expression vector with $2 \mathrm{~A}$ cleavage site upstream of hNET was taken forward for in vivo assessment. FLuc/hNET cells were successfully visualised using sequential BLI and SPECT imaging demonstrating high target to background tumour visualisation at $24 \mathrm{~h}$ post ${ }^{123}$ I-MIBG administration. 


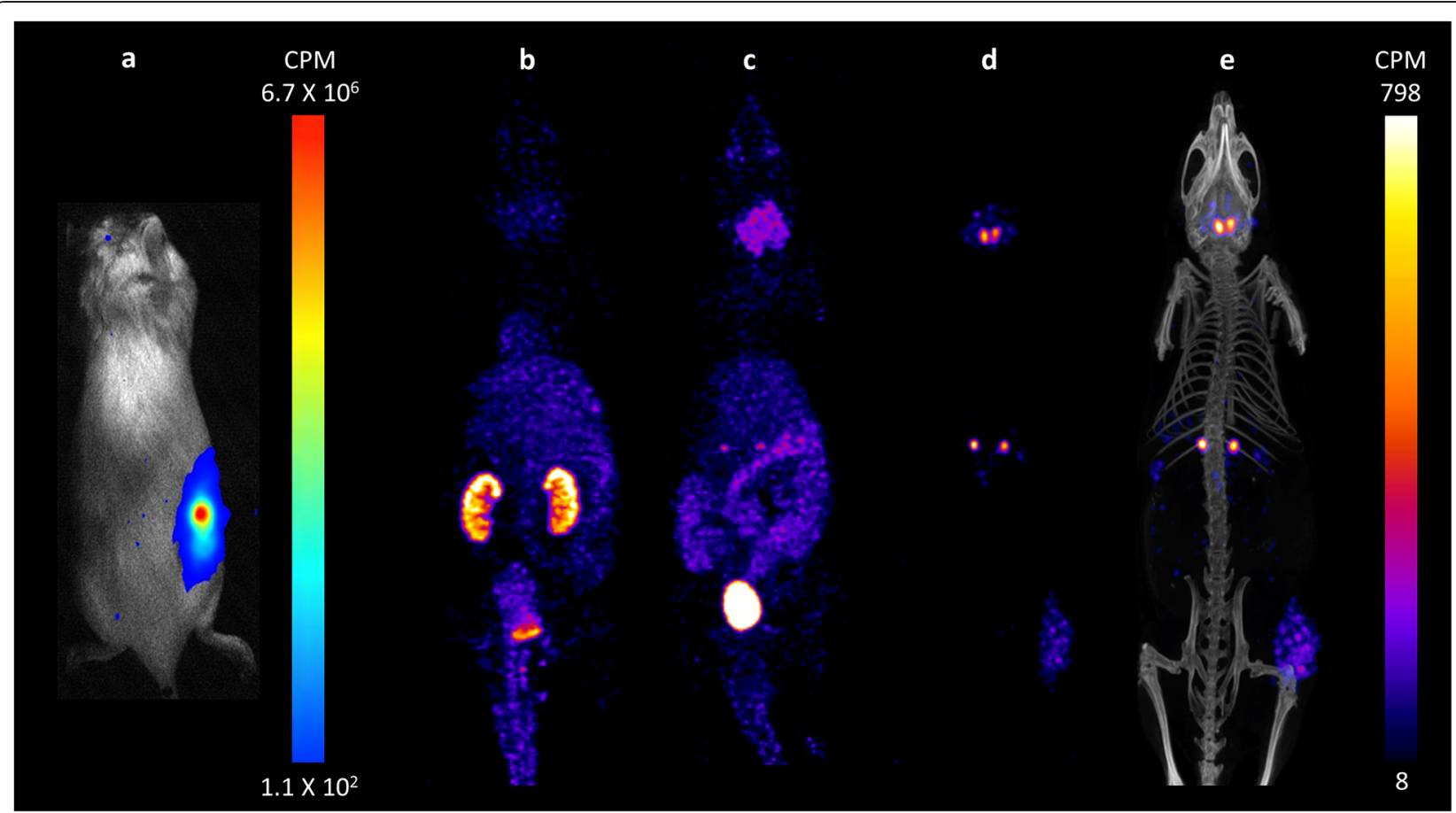

Figure 4 In vivo validation of the tricistronic vector hNET.2A.FLuc.2A.RQR8 via (a) BLI and (b-e) SPECT/CT. $5 \times 10^{6}$ SUPT1/hNET.2A.FLUc.2A RQR8 were inoculated into the right flank of immunocompromised mice. Regions of interest were drawn around the right flanks and mean luminescence signal intensity was measured $(n=3)$. (b-d) Maximum intensity projection (MIP) SPECT images and (e) SPECT/CT illustrate ${ }^{123}$ I-MIBG clearance via renal excretion, with increasing signal in the adrenals, thyroid, salivary glands and tumour $(\mathbf{d}$, e). Percent injected dose $(n=3)$ of ${ }^{123}$ I-MIBG within the tumours was determined by drawing 3D regions of interest. Colour bars represent counts per minute with maximum and minimum threshold levels indicated.

\section{Conclusions}

In conclusion, exploiting the unique fluorescent properties of $\mathrm{ASP}^{+}$, we have been able to explore hNET function in engineered cells. We have constructed a novel pre-clinical tricistronic vector with BLI, SPECT, flow cytometry and histochemical capabilities, which can be widely applied in cell tracking studies supporting the development of cell therapies. Further investigation with regard to quantitatively correlating $\mathrm{ASP}^{+}$and MIBG kinetics in hNET engineered cells, as well as determining the in vivo sensitivity of the technique is required and should be performed for each new cell line under investigation.

\section{Additional file}

Additional file 1: Table S1. Functional assessment of hNET cell lines over time. SupT1 cells expressing hNET.I.dCD34 (vector 1), SupT1/FLuc.2A. RQR8.2A.hNET (vector 2) and SupT1/hNET.2A.FLuc.2A.RQR8 (vector 3) were incubated with $\mathrm{ASP}^{+}$for 30 min at $37^{\circ} \mathrm{C}$ and the percentage of $\mathrm{ASP}^{+}$cells was assessed using flow cytometry at weeks 1, 7,11 and 17 post transduction.

\section{Authors' contributions}

$A B, L K, K S$ and $A J$ performed the experiments. $A B, L K$ and TK participated in data analysis. SK, MP and EA provided reagents and materials. AB, EA, ML and MP conceived and designed the experiments and contributed in the drafting of the manuscript. All authors read and approved the final manuscript.

\section{Authors' information}

Adam Badar and Louise Kiru are joint first authors. Martin Pule and Mark F Lythgoe are joint senior authors.

\section{Acknowledgements}

This work was financially supported by the following: The Comprehensive Cancer Imaging Centre at KCL \& UCL jointly funded by Cancer Research UK (CRUK) and the Engineering and Physical Sciences Research Council (EPSRC), the UK Regenerative Medicine Platform (UKRMP MR/K026739/1) Safety Hub MRC, EPSRC and BBSRC, and EPSRC Early Career Fellowship (EP/L006472/1) Generation of Multi-Modal Imaging Mesenchymal Stem Cells.

\section{Author details}

'Division of Medicine, Centre for Advanced Biomedical Imaging (CABI), University College London, 72 Huntley Street, London WC1E 6DD, UK. ${ }^{2}$ UCL Cancer Institute, University College London, 72 Huntley Street, London WC1E 6DD, UK. ${ }^{3}$ Department of Chemistry and Institute of Nuclear Medicine,

University College London, 235 Euston Road (T-5), London NW1 2BU, UK.

Received: 15 December 2014 Accepted: 10 March 2015

Published online: 28 March 2015

\section{References}

1. Pule MA, Savoldo B, Myers GD, Rossig C, Russell HV, Dotti G, et al. Virusspecific T cells engineered to coexpress tumor-specific receptors: 
persistence and antitumor activity in individuals with neuroblastoma. Nat Med. 2008;14(11):1264-70.

2. Porter DL, Levine BL, Kalos M, Bagg A, June $\mathrm{CH}$. Chimeric antigen receptormodified T cells in chronic lymphoid leukemia. N Engl J Med. 2011;365(8):725-33.

3. Kochenderfer JN, Dudley ME, Feldman SA, Wilson WH, Spaner DE, Maric I, et al. B-cell depletion and remissions of malignancy along with cytokineassociated toxicity in a clinical trial of anti-CD19 chimeric-antigen-receptortransduced T cells. Blood. 2012;119:2709-20.

4. Brentjens RJ, Davila ML, Riviere I, Park J, Wang X, Cowell LG, et al. CD19targeted $T$ cells rapidly induce molecular remissions in adults with chemotherapy-refractory acute lymphoblastic leukemia. Sci Transl Med. 2013;5:177ra38.

5. Lindvall O, Kokaia Z. Stem cells in human neurodegenerative disorders-time for clinical translation? J Clin Invest. 2010;120(1):29-40.

6. Miyahara Y, Nagaya N, Kataoka M, Yanagawa B, Tanaka K, Hao H, et al. Monolayered mesenchymal stem cells repair scarred myocardium after myocardial infarction. Nat Med. 2006;12(4):459-65.

7. Yoshioka T, Ageyama N, Shibata H, Yasu T, Misawa Y, Takeuchi K, et al. Repair of infarcted myocardium mediated by transplanted bone marrowderived CD34 + stem cells in a nonhuman primate model. Stem Cells. 2005;23(3):355-64.

8. Bruder SP, Fink DJ, Caplan Al. Mesenchymal stem cells in bone development, bone repair, and skeletal regeneration therapy. J Cell Biochem. 1994;56(3):283-94.

9. Balaban EP, Simon TR, Frenkel EP. Toxicity of indium-111 on the radiolabeled lymphocyte. J Nucl Med. 1987;28(2):229-33.

10. Brenner W, Aicher A, Eckey T, Massoudi S, Zuhayra M, Koehl U, et al. 111lnlabeled CD34+ hematopoietic progenitor cells in a rat myocardial infarction model. J Nucl Med. 2004:45(3):512-8.

11. Nowak B, Weber C, Schober A, Zeiffer U, Liehn EA, von Hundelshausen P, et al. Indium-111 oxine labelling affects the cellular integrity of haematopoietic progenitor cells. Eur J Nucl Med Mol Imaging. 2007;34(5):715-21.

12. Botti C, Negri DR, Seregni E, Ramakrishna V, Arienti F, Maffioli L, et al. Comparison of three different methods for radiolabelling humanactivated $T$ lymphocytes. Eur J Nucl Med Mol Imaging. 1997;24:497-504.

13. Carr HM, Smyth JV, Rooney OB, Dodd PD, Sharma H, Walker MG. Limitations of in-vitro labeling of endothelial cells with indium-111 oxine. Cell Transplant. 1995:4(3):291-6.

14. Li Z, Suzuki Y, Huang M, Cao F, Xie X, Connolly AJ, et al. Comparison of reporter gene and iron particle labeling for tracking fate of human embryonic stem cells and differentiated endothelial cells in living subjects. Stem Cells. 2008;26:864-7.

15. Kang JH, Chung JK. Molecular-genetic imaging based on reporter gene expression. J Nucl Med. 2008:49(2):164S-79.

16. Gambhir SS, Yaghoubi SS, Campbell RE, Davidson MW, Doyle TC, Wang Q et al. Molecular imaging with reporter genes. Cambridge University Press. 2010. ISBN: 9780521882330.

17. Anton M, Wagner B, Haubner R, Bodenstein C, Essien BE, Bönisch $H$, et al. Use of the norepinephrine transporter as a reporter gene for non-invasive imaging of genetically modified cells. J Gene Med. 2004;6(1):119-26.

18. Moroz MA, Serganova I, Zanzonico P, Ageyeva L, Beresten T, Dyomina E, et al. Imaging hNET reporter gene expression with 124I-MIBG. J Nucl Med. 2007:48(5):827-36.

19. Buursma AR, Beerens AM, de Vries EF, van Waarde A, Rots MG, Hospers GA et al. The human norepinephrine transporter in combination with $11 \mathrm{C}-\mathrm{m}$ hydroxyephedrine as a reporter gene/reporter probe for PET of gene therapy. J Nucl Med. 2005;46(12):2068-75.

20. Brader P, Kelly KJ, Chen N, Yu YA, Zhang Q, Zanzonico P, et al. Imaging a genetically engineered oncolytic vaccinia virus (GLV-1h99) using a human norepinephrine transporter reporter gene. Clin Cancer Res. 2009;15(11):3791-801.

21. Doubrovin MM, Doubrovina ES, Zanzonico P, Sadelain M, Larson SM, O'Reilly RJ. In vivo imaging and quantitation of adoptively transferred human antigen-specific T cells transduced to express a human norepinephrine transporter gene. Cancer Res. 2007;67(24):11959-69.

22. Philip B, Kokalaki E, Mekkaoui L, Thomas S, Straathof K, Flutter B, et al. A highly compact epitope-based marker / suicide gene for easier and safer Tcell therapy. Blood. 2014;124(8):1277-87.

23. Bönisch $H$, Brüss $M$. The norepinephrine transporter in physiology and disease. Handb Exp Pharmacol. 2006;175:485-524.
24. Mason JN, Farmer H, Tomlinson ID, Schwartz JW, Savchenko V, DeFelice L, et al. Novel fluorescence-based approaches for the study of biogenic amine transporter localization, activity, and regulation. J Neurosci Methods. 2005;143(1):3-25

25. Branchini BR, Ablamsky DM, Davis AL, Southworth TL, Butler B, Fan F, et al. Red-emitting luciferases for bioluminescence reporter and imaging applications. Anal Biochem. 2010;396(2):290-7.

26. Szymczak AL, Workman CJ, Wang Y, Vignali KM, Dilioglou S, Vanin EF, et al. Correction of multi-gene deficiency in vivo using a single 'self-cleaving' $2 \mathrm{~A}$ peptide-based retroviral vector. Nat Biotechnol. 2004;22(5):589-94.

27. Peñuelas I, Mazzolini G, Boán JF, Sangro B, Martí-Climent J, Ruiz M, et al. Positron emission tomography imaging of adenoviral-mediated transgene expression in liver cancer patients. Gastroenterology. 2005;128(7):1787-95.

28. Jacobs A, Voges J, Reszka R, Lercher M, Gossmann A, Kracht L, et al. Positron-emission tomography of vector-mediated gene expression in gene therapy for gliomas. Lancet. 2001;358(9283):727-9.

29. Yaghoubi S, Jensen MC, Satyamurthy N, Budhiraja S, Paik D, Czernin J, et al. Non-invasive detection of therapeutic cytolytic T cells with [18F]FHBG positron emission tomography in a glioma patient. Nat Clin Pract Oncol. 2008;6(1):53-8.

30. Shin JH, Chung JK, Kang JH, Lee YJ, Kim KI, Kim CW, et al. Feasibility of sodium/iodide symporter (NIS) gene as a new imaging reporter gene: comparison with HSV1-tk. Eur J Nucl Med Mol Imaging. 2004;31:425-32.

31. Gambhir SS, Barrio JR, Wu L, lyer M, Namavari M, Satyamurthy N, et al. Imaging of adenoviral-directed herpes simplex virus type 1 thymidine kinase reporter gene expression in mice with radiolabeled ganciclovir. J Nucl Med. 1998;39:2003-11.

32. Wang B, Li J, Fu FH, Chen C, Zhu X, Zhou L, et al. Construction and analysis of compact muscle-specific promoters for AAV vectors. Gene Ther. 2008;15(22):1489-99.

33. Chan HY VS, Xing X, Kraus P, Yap SP, Ng P, et al. Comparison of IRES and F2A-based locus-specific multicistronic expression in stable mouse lines. PLoS One. 2011;6(12):e28885

34. Kim JH, Lee SR, Li LH, Park HJ, Park JH, Lee KY, et al. High cleavage efficiency of a $2 A$ peptide derived from porcine teschovirus- 1 in human cell lines, zebrafish and mice. PLoS One. 2011;6(4):e18556.

35. Qin C, Cheng K, Chen K, Hu X, Liu Y, Lan X, et al. Tyrosinase as a multifunctional reporter gene for photoacoustic/MRI/PET triple modality molecular imaging. Sci Rep. 2013;3:1490.

36. Patrick PS, Hammersley J, Loizou L, Kettunen MI, Rodrigues TB, Hu DE, et al. Dual-modality gene reporter for in vivo imaging. Proc Natl Acad Sci. 2013;111(1):415-20.

37. Distelmaier F, Wiedemann $\mathrm{P}$, Brüss $\mathrm{M}$, Bönisch $\mathrm{H}$. Functional importance of the C-terminus of the human norepinephrine transporter. J Neurochem. 2004;91(3):537-46.

38. Sogawa C, Kumagai K, Sogawa N, Morita K, Dohi T, Kitayama S. C-terminal region regulates the functional expression of human noradrenaline transporter splice variants. Biochem J. 2007:401(1):185-95.

\section{Submit your manuscript to a SpringerOpen ${ }^{\circ}$ journal and benefit from:}

- Convenient online submission

- Rigorous peer review

- Immediate publication on acceptance

- Open access: articles freely available online

- High visibility within the field

- Retaining the copyright to your article

Submit your next manuscript at $>$ springeropen.com 